\title{
Effect of Oral Semaglutide on the Pharmacokinetics of Levonorgestrel and Ethinylestradiol in Healthy Postmenopausal Women and Furosemide and Rosuvastatin in Healthy Subjects
}

\author{
Andreas B. Jordy ${ }^{1} \cdot$ Muna Albayaty ${ }^{2} \cdot$ Astrid Breitschaft $^{3} \cdot$ Thomas W. Anderson $^{1} \cdot$ Erik Christiansen $^{1}$. \\ Azadeh Houshmand- $\varnothing$ regaard ${ }^{1}$. Easwaran Manigandan ${ }^{4} \cdot$ Tine A. Bækdal $^{1}$
}

Published online: 30 March 2021

(c) The Author(s) 2021

\begin{abstract}
Background The first oral glucagon-like peptide-1 receptor agonist (GLP-1RA) comprises semaglutide co-formulated with the absorption enhancer, sodium $N$-(8-[2-hydroxybenzoyl] amino) caprylate (SNAC). Oral semaglutide may alter the pharmacokinetics of co-administered drugs via effects of semaglutide or SNAC. Two separate one-sequence crossover trials investigated the effects of oral semaglutide and SNAC on the pharmacokinetics of ethinylestradiol, levonorgestrel, furosemide and rosuvastatin.

Methods Healthy, postmenopausal women ( $n=25)$ received once-daily combined ethinylestradiol and levonorgestrel (Trial 1$)$ and healthy male and female subjects $(n=41)$ received single doses of furosemide and rosuvastatin (Trial 2), either alone, with SNAC alone or with oral semaglutide. Lack of drug-drug interaction was concluded if $90 \%$ confidence intervals (CIs) for the ratio of area under the plasma concentration-time curve (AUC) or maximum concentration $\left(C_{\max }\right)$, with/without oral semaglutide, were within a pre-specified interval (0.80-1.25).

Results The AUC values of ethinylestradiol and levonorgestrel were not affected by oral semaglutide co-administration (estimated ratios [90\% CI] 1.06 [1.01-1.10] and 1.06 [0.97-1.17], respectively); $C_{\max }$ was not affected. The no-effect criterion was not met for furosemide or rosuvastatin for the AUC (1.28 [1.16-1.42] and 1.41 [1.24-1.60], respectively) or $C_{\max }$. SNAC alone did not affect the AUC or $C_{\max }$ of ethinylestradiol, levonorgestrel or rosuvastatin; the $C_{\max }$ of furosemide was slightly decreased. Adverse events were similar to those previously observed for GLP-1RAs (both trials).

Conclusion Co-administration with oral semaglutide did not affect the pharmacokinetics of ethinylestradiol or levonorgestrel. There was a small increase in exposure of furosemide and rosuvastatin; however, these increases are not expected to be of clinical relevance.
\end{abstract}

Clinical Trial Registration Numbers NCT02845219 and NCT03010475.

\section{Key Points}

The victim drugs ethinylestradiol, levonorgestrel, furosemide and rosuvastatin are commonly used drugs in patients with type 2 diabetes.

Tine A. Bækdal

tabq@novonordisk.com

1 Novo Nordisk A/S, Vandtårnsvej 108-110, 2860 Søborg, Denmark

2 Parexel Early Phase Clinical Unit, Northwick Park Hospital, Parexel International, Watford Road, Harrow HA1 3UJ, UK

3 Parexel International GmbH, Klinikum Westend, Haus 18, Spandauer Damm 130, 14050 Berlin, Germany

4 Novo Nordisk Service Centre India Private Ltd., Plot No. 148, 2nd Floor, Prestige Featherlite Tech Park, 2nd Phase, EPIP Area, Whitefield, Bangalore 560 066, India

Oral semaglutide had no statistically significant effect on the exposure of ethinylestradiol or levonorgestrel but resulted in a small increase in the exposure of furosemide and rosuvastatin, which is not expected to be of clinical relevance.

Oral semaglutide was found to be well-tolerated in combination with these drugs and no new safety issues were identified. 


\section{Introduction}

Glucagon-like peptide-1 receptor agonists (GLP-1RAs) are an effective treatment option for type 2 diabetes (T2D). Several GLP-1RAs are currently marketed, all of which are administered by subcutaneous injection [1]. Once-weekly subcutaneous administration of the GLP-1 analogue semaglutide has been shown to improve glycaemic control and reduce body weight in patients with T2D [2-6]. Semaglutide has $94 \%$ sequence homology to native human GLP-1 [7]. Structural differences between native GLP-1 and semaglutide include amino acid substitutions at position 8 (alanine to $\alpha$-aminoisobutyric acid) and position 34 (lysine to arginine), and acylation of the lysine in position 26 with a spacer and C-18 fatty diacid chain [8]. The substitution at position 8 makes semaglutide less susceptible to degradation by dipeptidyl peptidase-4 [9], while the spacer and fatty diacid mediate strong binding to albumin [10].

Oral semaglutide is a novel tablet comprising the active pharmaceutical ingredient (API) semaglutide co-formulated with an absorption enhancer, sodium $N$-(8-[2-hydroxybenzoyl] amino) caprylate (SNAC; $300 \mathrm{mg}$ ) [11], which protects semaglutide against enzymatic degradation through a localised increase in $\mathrm{pH}$ and transiently enhances absorption across the gastric epithelium via the transcellular route [12, 13]. Oral administration of GLP-1-based therapies offers the potential for earlier treatment and may improve patient acceptance and adherence for more patients with T2D [14]. In clinical trials, oral semaglutide has demonstrated substantial dose-dependent lowering of both glycated haemoglobin $\left(\mathrm{HbA}_{1 \mathrm{c}}\right)$ and body weight [15-17], with a safety profile in line with other GLP-1RAs [15, 18].

In previous studies, there was no apparent effect of renal impairment on the pharmacokinetics of oral semaglutide [19], and semaglutide plasma exposure appeared similar across hepatic function groups in subjects with hepatic impairment [20]. In an absorption, metabolism and excretion trial with subcutaneous semaglutide, it was shown that semaglutide is metabolised prior to excretion, with semaglutide-related material excreted in both urine (only 3\% elimination of intact semaglutide) and faeces [7]. In addition, cytochrome P450 (CYP) enzymes and transporters are not expected to be inhibited or induced by semaglutide [9].

Like other GLP-1RAs [21], semaglutide administration results in a small delay in gastric emptying during the first hour after a meal [22]. Oral semaglutide may potentially alter the pharmacokinetics of concomitantly administered drugs (victim drugs) via the effect on gastric emptying (as has been shown for other GLP-1RAs [21]) or via the effects of the absorption enhancer SNAC, although recent drug-drug interaction (DDI) studies found that oral semaglutide had no clinically meaningful effect on the exposure of four victim drugs (lisinopril, warfarin, digoxin and metformin) commonly used in patients with T2D [23].

Metabolism of ethinylestradiol and levonorgestrel occurs mainly in the liver but also in the gastrointestinal tract [24] via CYP enzymes, particularly by CYP3A4, which is expressed in the liver and intestine [25]. In addition, ethinylestradiol is metabolised by conjugation by uridine diphosphate glucuronosyltransferase (UGT) 1A1 [26] and oestrogen sulfotransferase 1E1 [27]. As in vitro studies have shown very low potential for semaglutide to inhibit or induce CYP enzymes, or to inhibit drug transporters [9], and other in vitro studies demonstrated that SNAC does not inhibit or induce any of the CYP enzymes or inhibit UGT enzymes [28], the risk of DDIs between oral semaglutide and ethinylestradiol and levonorgestrel is considered low. However, the intended population to be treated with oral semaglutide is likely to include women of child-bearing potential receiving oral contraception. Therefore, in vivo confirmation in women is required to provide evidence that the systemic exposure of ethinylestradiol or levonorgestrel will not be impacted by co-administration of oral semaglutide.

Furosemide is a loop diuretic used to treat oedema associated with cardiac, renal and hepatic failure. The bioavailability of furosemide is poor when administered orally, and can vary greatly between individuals [29]. Rosuvastatin is a statin (HMG-CoA reductase inhibitor) used for the treatment of dyslipidaemia. The bioavailability of orally administered rosuvastatin is approximately $20 \%$ [30, 31]. In vitro data suggest that SNAC may inhibit uptake and efflux transporters, such as the breast cancer resistance protein (BCRP) and organic-anion-transporter (OAT) 1 and/or 3 and OAT polypeptide OATP1B1, potentially leading to increased plasma levels of certain transporter substrates [32]. US Food and Drug Administration (FDA) guidelines list furosemide as a suitable victim drug to test potential DDIs for OAT1 and/or OAT3 and rosuvastatin as a suitable victim drug to test potential DDIs for BCRP, OAT1 and/or OAT3 and OATP1B1 [33].

Here, we report the results of two trials that were conducted to investigate the effects of oral semaglutide on the pharmacokinetics of a combined oral contraceptive (OC) containing ethinylestradiol and levonorgestrel (Trial 1, NCT02845219 [34]), and furosemide and rosuvastatin (Trial 2, NCT03010475 [35]).

\section{Methods}

\subsection{Trial Design and Populations}

Relevant Ethics Committees (Trial 1: Landesamt für Gesundheit und Soziales und Geschäftsstelle der Ethikkommission 
des Landes, Berlin, Germany; Trial 2: Brent Research Ethics Committee, London, UK) approved the trial protocols. Trial 1 was conducted at Parexel International GmbH, Berlin and Trial 2 was conducted at Northwick Park Hospital, Parexel Early Phase Clinical Unit, London. All subjects provided written informed consent prior to trial-related activities and both trials were conducted in accordance with the Declaration of Helsinki [36], International Conference on Harmonisation of Technical Requirements for Registration of Pharmaceuticals for Human Use Good Clinical Practice [37] and FDA 21 Code of Federal Regulations 312.120 [38] guidelines. According to FDA and European Medicines Agency (EMA) guidelines for DDI trials [39, 40], the systemic exposure of the perpetrator drug (oral semaglutide) should generally be the exposure obtained with the highest recommended dose under therapeutic (steady state) conditions. The highest therapeutic dose of oral semaglutide is $14 \mathrm{mg}$ and, consequently, the potential interactions were assessed at this dose at steady state. As semaglutide has a half-life of approximately 1 week, dosing with once-daily oral semaglutide $14 \mathrm{mg}$ for 4 weeks prior to assessment of interaction was considered adequate. Guidelines also state that the exposure of the victim drugs should be relevant to their clinical use $[39,40]$ and the doses selected for levonorgestrel, ethinylestradiol, furosemide and rosuvastatin were $0.15 \mathrm{mg}, 0.03 \mathrm{mg}, 40 \mathrm{mg}$ and $20 \mathrm{mg}$, respectively. Furosemide and rosuvastatin were given as single doses, whereas the OCs were dosed to steady state in order to provide clinically relevant exposures while taking pharmacokinetics and tolerability of the compounds into consideration. A treatment period of the victim drug (OC, furosemide or rosuvastatin) co-administered with SNAC alone was also included in order to differentiate between the possible effects of semaglutide and SNAC (Fig. 1).

Both trials had an open-label, one-sequence, crossover trial design. In Trial 1, postmenopausal women (aged $\geq 45$ years with $\geq 12$ consecutive months since last spontaneous menstrual bleeding) were included in order to avoid any potential effect on pharmacokinetics of levonorgestrel and ethinylestradiol caused by physiological hormonal fluctuations seen in women of childbearing potential. Trial 2 included healthy male and female subjects aged 18-65 years. In both trials, body mass index was required to be $20.0-29.9 \mathrm{~kg} / \mathrm{m}^{2}$. Subjects were considered generally healthy based on medical history, physical examination, electrocardiogram and clinical laboratory tests. Full exclusion criteria are listed in the Electronic Supplementary Material (ESM; Online Resource 1, Table S1).

\subsection{Treatments}

In each trial, the victim drug was administered in three periods: (1) alone; (2) with SNAC alone; or (3) with oral semaglutide. Oral semaglutide is a co-formulation of the API semaglutide and the absorption enhancer SNAC $300 \mathrm{mg}$.

\subsubsection{Trial 1 (Ethinylestradiol/Levonorgestrel)}

Subjects received a once-daily OC (Microgynon ${ }^{\circledR}$ containing ethinylestradiol $0.03 \mathrm{mg}$ and levonorgestrel $0.15 \mathrm{mg}$ ) in three 8 -day periods. In the first period, the $\mathrm{OC}$ was administered alone (OC); in the second period, the $\mathrm{OC}$ was administered concomitantly with a tablet of SNAC $300 \mathrm{mg}(\mathrm{OC}+$ SNAC) and SNAC once-daily dosing was continued for 8 days to ensure SNAC exposure during the OC pharmacokinetic sampling period. Once-daily treatment with oral semaglutide was then initiated and subjects were dose-escalated weekly from 3 to $7 \mathrm{mg}$, and then from 7 to $14 \mathrm{mg}$. Subjects were then maintained on oral semaglutide $14 \mathrm{mg}$ for 4 weeks to reach semaglutide steady state before the start of the third treatment period, where the $\mathrm{OC}$ was administered concomitantly with oral semaglutide (OC + oral semaglutide). Each treatment period was followed by 10 days of ethinylestradiol and levonorgestrel pharmacokinetic sampling (Fig. 1a). Oral semaglutide administration was continued to maintain exposure during the 10 days of ethinylestradiol and levonorgestrel pharmacokinetic sampling.

\subsubsection{Trial 2 (Furosemide/Rosuvastatin)}

In Trial 2, furosemide $40 \mathrm{mg}$ and rosuvastatin $20 \mathrm{mg}$ were administered in three periods, as separate single doses on consecutive days, i.e. with a 24 -h washout period in between each dose. In the first period, furosemide and rosuvastatin were administered alone (without perpetrator drug). In the second period, furosemide and rosuvastatin were co-administered with a tablet of SNAC $300 \mathrm{mg}$ (furosemide/rosuvastatin + SNAC) and SNAC once-daily dosing was continued for 4 days to ensure SNAC exposure until the rosuvastatin pharmacokinetic sampling period was completed. Oncedaily treatment with oral semaglutide was initiated and subjects were dose-escalated weekly from 3 to $7 \mathrm{mg}$, and then from 7 to $14 \mathrm{mg}$. Subjects were maintained on oral semaglutide $14 \mathrm{mg}$ for 4 weeks to reach semaglutide steady state before the start of the third treatment period, where furosemide and rosuvastatin were administered concomitantly with oral semaglutide (furosemide/rosuvastatin + oral semaglutide). In all three periods, pharmacokinetic sampling for furosemide and rosuvastatin was performed up to 12 and $96 \mathrm{~h}$ after dosing, respectively (Fig. 1b).

In Trial 1 and Trial 2, co-administered trial products were taken simultaneously or immediately after each other (within $2 \mathrm{~min}$ ).

In both trials, safety and tolerability of oral semaglutide were also assessed. To confirm exposure of semaglutide and SNAC, pharmacokinetic assessment for semaglutide 
(a) Trial 1

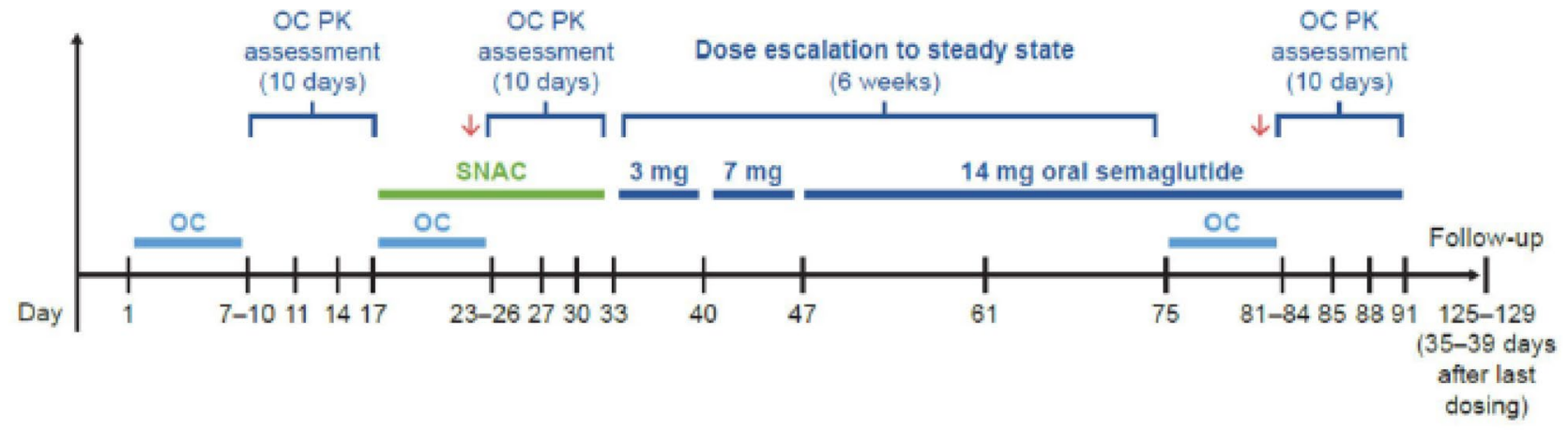

(b) Trial 2

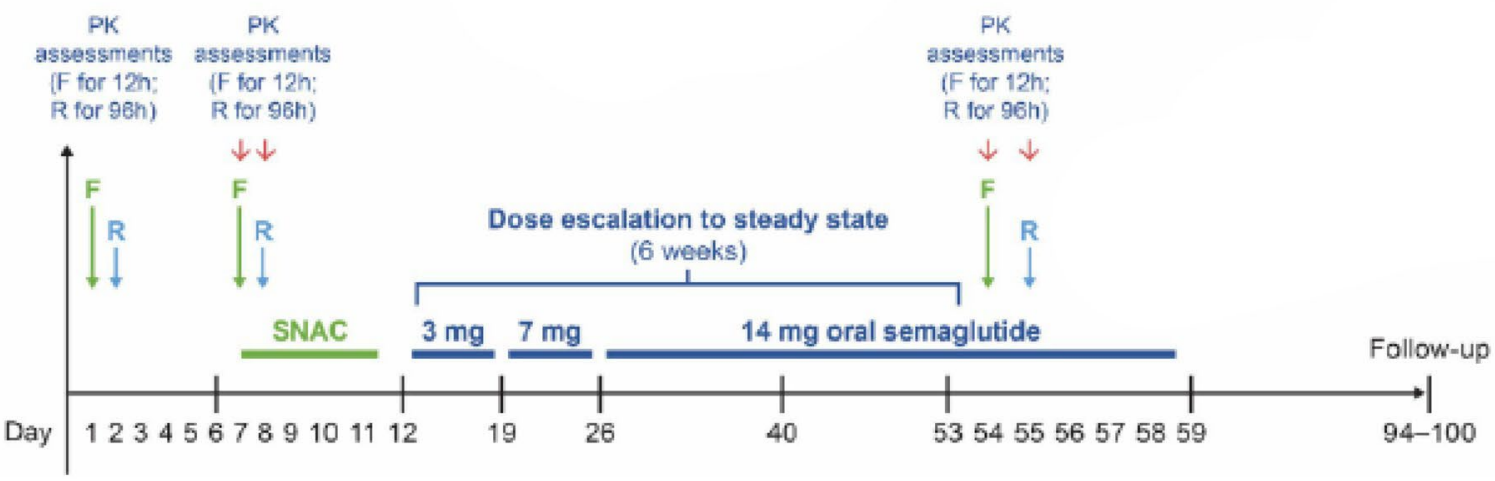

Fig. 1 Trial design for a Trial 1 (combined OC) and b Trial 2 (furosemide/rosuvastatin). Oral semaglutide is the formulation of the active pharmaceutical ingredient semaglutide and the absorption enhancer SNAC $300 \mathrm{mg}$. $F$ furosemide $(40 \mathrm{mg}$ ), $O C$ combined

was made at steady state conditions with oral semaglutide $14 \mathrm{mg}$ and for SNAC in the OC + SNAC and furosemide/ rosuvastatin + SNAC periods, respectively (Fig. 1a, b).

\subsection{Endpoints}

The primary endpoints were area under the plasma concentration-time curve (AUC) from time 0 to $24 \mathrm{~h}$ at steady state $\left(\mathrm{AUC}_{0-24, \mathrm{SS}}\right)$ for ethinylestradiol $\left(\mathrm{AUC}_{0-24, \mathrm{EE}, \mathrm{SS}}\right)$ and levonorgestrel $\left(\mathrm{AUC}_{0-24, \mathrm{LN}, \mathrm{SS}}\right)$ (Trial 1) and $\mathrm{AUC}$ from time zero to infinity $\left(\mathrm{AUC}_{0-\infty}\right)$ for single doses $\left(\mathrm{AUC}_{0-\infty, \mathrm{SD}}\right)$ of furosemide $\left(\mathrm{AUC}_{0-\infty, \text { furo,SD }}\right)$ and rosuvastatin $\left(\mathrm{AUC}_{0-\infty, \mathrm{rosu}, \mathrm{SD}}\right)$ (Trial 2). Secondary endpoints were maximum concentration $\left(C_{\max }\right)$, time to $C_{\max }\left(t_{\max }\right)$ and terminal half-life $\left(t_{1 / 2}\right)$ for all four victim drugs. oral contraceptive [ethinylestradiol $(0.03 \mathrm{mg})$ and levonorgestrel $(0.15 \mathrm{mg})], P K$ pharmacokinetic, $R$ rosuvastatin $(20 \mathrm{mg}), S N A C$ sodium $N$-(8-[2-hydroxybenzoyl] amino) caprylate $(300 \mathrm{mg}), \downarrow$ indicates semaglutide and SNAC PK assessments

\subsection{Analytical and Statistical Methods}

\subsubsection{Pharmacokinetic Assessments}

2.4.1.1 Bioanalysis The methods for semaglutide and SNAC bioanalysis have previously been described [20]. Validated liquid chromatography mass spectrometry (LC-MS/MS) assays were used to investigate plasma concentrations of the four victim drugs: ethinylestradiol, levonorgestrel, furosemide and rosuvastatin. Full details are described in ESM Online Resource 1, Table S2.

Pre-dose values that were below the lower limit of quantification (LLOQ) were set to zero. Intermediate samples (after dosing and before the last quantifiable observation) were set to LLOQ/2. LLOQ values obtained after the last 
quantifiable observation were imputed based on $t_{1 / 2}$. If $t_{1 / 2}$ was unavailable, then the first value after the last quantifiable observation was set to $L L O Q / 2$ and the remaining values were set to zero.

2.4.1.2 Determination of Sample Size Based on 21 subjects completing the trial, Trial 1 was calculated to have an overall combined statistical power of at least $80 \%$ of concluding no effect for the four endpoints (i.e. $\mathrm{AUC}_{0-24, \mathrm{SS}}$ and $C_{\max }$ at steady state $\left[C_{\max , S S}\right]$ for both ethinylestradiol and levonorgestrel), assuming AUC and $C_{\max }$ ratios of 0.93 when comparing ethinylestradiol/levonorgestrel co-administered with oral semaglutide versus ethinylestradiol/levonorgestrel alone. The within-subject standard deviations (SDs) for ethinylestradiol were 0.149 and 0.215 for $\log \left(\mathrm{AUC}_{0-24, \mathrm{SS}}\right)$ and $\log \left(C_{\text {max,SS }}\right)$, respectively. The within-subject SDs for levonorgestrel were 0.165 and 0.236 for $\log \left(\mathrm{AUC}_{0-24, \mathrm{SS}}\right)$ and $\log \left(C_{\text {max }, \mathrm{SS}}\right)$, respectively. Due to the long duration of the trial with no replacement of subjects in case of withdrawals, 25 subjects were included.

Based on 36 subjects completing the trial, Trial 2 was calculated to have an overall combined statistical power of $80 \%$ of concluding no effect for the four endpoints (i.e. $\mathrm{AUC}_{0-\infty, \mathrm{SD}}$ and $C_{\max }$ for single doses $\left[C_{\max , \mathrm{SD}}\right.$ ] for both furosemide and rosuvastatin), assuming AUC and $C_{\max }$ ratios of 0.95 when comparing furosemide/rosuvastatin co-administered with oral semaglutide versus furosemide/rosuvastatin alone. The within-subject SDs for furosemide were estimated to be 0.217 and 0.215 for $\log \left(\mathrm{AUC}_{0-\infty, \mathrm{SD}}\right)$ and $\log \left(C_{\max , \mathrm{SD}}\right)$, respectively. The within-subject SDs for rosuvastatin were estimated to be 0.191 and 0.244 for $\log \left(\mathrm{AUC}_{0-\infty, \mathrm{SD}}\right)$ and $\log \left(C_{\max , \mathrm{SD}}\right)$, respectively. Allowing up to $12 \%$ dropout, 41 subjects were included. During the trial, blood samples from six subjects for rosuvastatin pharmacokinetic analysis were accidentally thawed during shipment, making the assessment of rosuvastatin pharmacokinetic endpoints impossible for these subjects. In addition, two subjects were withdrawn from the trial, resulting in 33 subjects with evaluable data for the rosuvastatin pharmacokinetic endpoints. The loss in statistical power was considered to be acceptable and therefore no extra subjects were enrolled in the trial. The statistical power in both trials was calculated using two one-sided $t$ tests of the means on log scale, each with a 5\% significance level. The pre-specified $90 \%$ confidence interval (CI) of 0.80-1.25 was considered as the 'no effect' interval.

The primary endpoints $\left(\mathrm{AUC}_{0-24, \mathrm{SS}}\right.$ of ethinylestradiol and levonorgestrel and $\mathrm{AUC}_{0-\infty}$ of furosemide and rosuvastatin) were log-transformed and analysed in a linear normal model with subject and period (oral semaglutide co-administration [with/without]) as fixed effects. Estimated differences in log-transformed values were back-transformed to the original scale and presented as ratios together with the corresponding two-sided
$90 \%$ CI. For both trials, a lack of effect was concluded if the $90 \% \mathrm{CI}$ for the ratio of the $\mathrm{AUC}_{0-24, \mathrm{Ss}}$ (Trial 1) or $\mathrm{AUC}_{0-\infty}$, (Trial 2) with/without oral semaglutide was within the pre-specified interval of 0.80-1.25. Similar analyses were performed for $C_{\max }$ and other secondary endpoints were analysed descriptively.

In both trials, the full analysis set and safety analysis set included all subjects who were exposed to at least one dose of a trial product.

\section{Results}

\subsection{Demographics}

In Trial 1, 25 healthy postmenopausal women were exposed to the trial products and completed the trial. In Trial 2, 41 healthy male and female subjects were exposed to the trial product and two withdrew consent after exposure-one subject withdrew after administration of rosuvastatin alone and one subject withdrew after starting oral semaglutide treatment; neither withdrawal was due to any adverse events (AEs). The remaining 39 subjects completed the trial and all 41 subjects were included in the full and safety analysis sets. Demographics and baseline characteristics are presented in Table 1.

\subsection{Pharmacokinetics}

\subsubsection{Trial 1 (Ethinylestradiol/Levonorgestrel)}

Mean concentration-time profiles for ethinylestradiol and levonorgestrel for the three treatment periods $(\mathrm{OC}, \mathrm{OC}+$ SNAC, OC + oral semaglutide) are presented in Fig. 2a, b.

3.2.1.1 Ethinylestradiol/Levonorgestrel The estimated treatment ratio of $\mathrm{AUC}_{0-24, \mathrm{SS}}$ for ethinylestradiol was 1.06 and the 90\% CI (1.01-1.10) was within the pre-specified 'no effect' interval. The estimated ratio of $\mathrm{AUC}_{0-24, \mathrm{SS}}$ for levonorgestrel was 1.06 and the $90 \% \mathrm{CI}(0.97-1.17)$ was also within the pre-specified 'no effect' interval. Similarly, the $90 \%$ CIs for the estimated ratios of $C_{\max }$ for ethinylestradiol and levonorgestrel were within the pre-specified interval (Fig. 3a), indicating that co-administration of oral semaglutide had no effect on the exposure of ethinylestradiol or levonorgestrel. Other secondary endpoints, including $t_{\max }$ and $t_{1 / 2}$, were similar for all three treatment periods (Tables 2 and 3 ).

\subsubsection{Semaglutide and Sodium N-(8-[2-Hydroxybenzoyl]} Amino) Caprylate (SNAC) Pharmacokinetic parameters for semaglutide and SNAC are shown in ESM Online Resource 1, Table S3a. The geometric mean $C_{\max }$ of semaglutide was $25.7 \mathrm{nmol} / \mathrm{L}$. 
Table 1 Demographics and baseline characteristics

\begin{tabular}{lll}
\hline Demographic/characteristic & $\begin{array}{l}\text { Trial } 1 \\
(\text { ethinylestradiol/levonorgestrel }) \\
(n=25)\end{array}$ & $\begin{array}{l}\text { Trial } 2 \\
(\text { furosemide/rosuvastatin }) \\
(n=41)\end{array}$ \\
\hline $\begin{array}{l}\text { Mean age, years (min; max) } \\
\text { Sex, } n(\%)\end{array}$ & $62(50 ; 75)$ & $39(18 ; 65)$ \\
Female & $25(100)$ & $10(24.4)$ \\
Male & $0(0)$ & $31(75.6)$ \\
Race, $n(\%)$ & $25(100)$ & $31(75.6)$ \\
White & 0 & $8(19.5)$ \\
Black or African American & 0 & $2(4.9)$ \\
Other & $65.5(55.8 ; 77.8)$ & $77.0(50.7 ; 95.7)$ \\
Mean body weight, kg (min; $\max )$ & $24.1(21.7 ; 28.8)$ & $25.0(20.1 ; 29.8)$ \\
Mean BMI, kg/m $(\min ; \max )$ & $5.6(5.3 ; 6.2)$ & $5.4(4.7 ; 6.1)$ \\
Mean $\mathrm{HbA}_{1 \mathrm{c}}, \%(\min ; \max )$ & & \\
\hline
\end{tabular}

$B M I$ body mass index, $H b A_{l c}$ glycated haemoglobin, $\max$ maximum, min minimum

\subsubsection{Trial 2 (Furosemide/Rosuvastatin)}

Mean concentration-time profiles for furosemide and rosuvastatin with/without oral semaglutide are shown in Fig. 2c, d.

3.2.2.1 Furosemide The estimated ratio for the $\mathrm{AUC}_{0-\infty}$ of furosemide co-administered with oral semaglutide compared with the $\mathrm{AUC}_{0-\infty}$ of furosemide alone was 1.28 and the $90 \%$ CI (1.16-1.42) was not within the pre-specified 'no effect' interval. Additionally, the 'no effect' criterion was not met for the $C_{\max }$ of furosemide (Fig. 3b). When co-administered with SNAC alone, there was no effect on the $\mathrm{AUC}_{0-\infty}$ of singledose furosemide while the $C_{\max }$ was slightly decreased. The median $t_{\max }$ was similar for furosemide when dosed alone and when co-administered with SNAC alone, but slightly later when co-administered with oral semaglutide. The $t_{1 / 2}$ of furosemide was similar for all three treatment periods (Table 4).

3.2.2.2 Rosuvastatin When co-administered with oral semaglutide, the estimated ratio for $\mathrm{AUC}_{0-\infty}$ of rosuvastatin was 1.41 and the $90 \% \mathrm{CI}(1.24-1.60)$ was not within the prespecified interval. Additionally, the 'no effect' criterion was not met for the $C_{\max }$ of rosuvastatin (Fig. 3b). The $\mathrm{AUC}_{0-\infty}$ and $C_{\max }$ values of rosuvastatin were not affected by co-administration of SNAC alone (Fig. 3b). The median $t_{\max }$ was similar for rosuvastatin when dosed alone and when co-administered with SNAC alone, but slightly later when co-administered with oral semaglutide. The $t_{1 / 2}$ of rosuvastatin was similar for all three treatment periods (Table 5).

3.2.2.3 Semaglutide and SNAC Pharmacokinetic parameters for semaglutide and SNAC are shown in ESM Online Resource 1, Table S3b. The geometric mean $C_{\max }$ of semaglutide was $28.4 \mathrm{nmol} / \mathrm{L}$.

\subsection{Safety and Tolerability}

\subsubsection{Trial 1 (Ethinylestradiol/Levonorgestrel)}

A total of 24 subjects had at least one AE during Trial 1. There were no deaths or serious AEs, no severe AEs and no AEs leading to withdrawal from the trial. An overview of treatment-emergent AEs is shown in Table 6. The most commonly reported AEs were gastrointestinal disorders, occurring in $80 \%(20 / 25)$ of subjects, primarily nausea, which occurred in 64\% (16/25) of subjects. Most gastrointestinalrelated AEs occurred during the dose-escalation period of oral semaglutide treatment and continued during co-administration with the OC. Reproductive system and breast disorders were the second most commonly reported AEs by organ class, reported in 68\% (17/25) of subjects (Table 6), of which vaginal haemorrhaging was the most common event, occurring in $64 \%(16 / 25)$ of subjects. The onset of vaginal haemorrhaging occurred in all three $\mathrm{OC}$ treatment periods, with more subjects having vaginal haemorrhaging during the OC + SNAC [60\% (15/25)] and OC + oral semaglutide $[44 \%(11 / 25)]$ treatment periods than with OC alone $[12 \%(3 / 25)]$. Metabolism and nutritional disorders were the third most commonly reported AEs, mainly in the form of decreased appetite, occurring in $80 \%(20 / 25)$ of subjects. In addition, seven AEs relating to laboratory abnormalities of increased liver enzymes were reported in five subjects during OC administration; six events were related to alanine transaminase (ALT), one event was related to aspartate transaminase (AST), and one subject had both AST and ALT elevation. All seven events were moderate in severity and none lasted more than 9 days. Overall, mean levels of both AST and ALT remained within the normal ranges and returned to normal at the end of each OC period. 
(a) Ethinylestradiol (steady state) \pm oral semaglutide \pm SNAC alone $(N=25)$

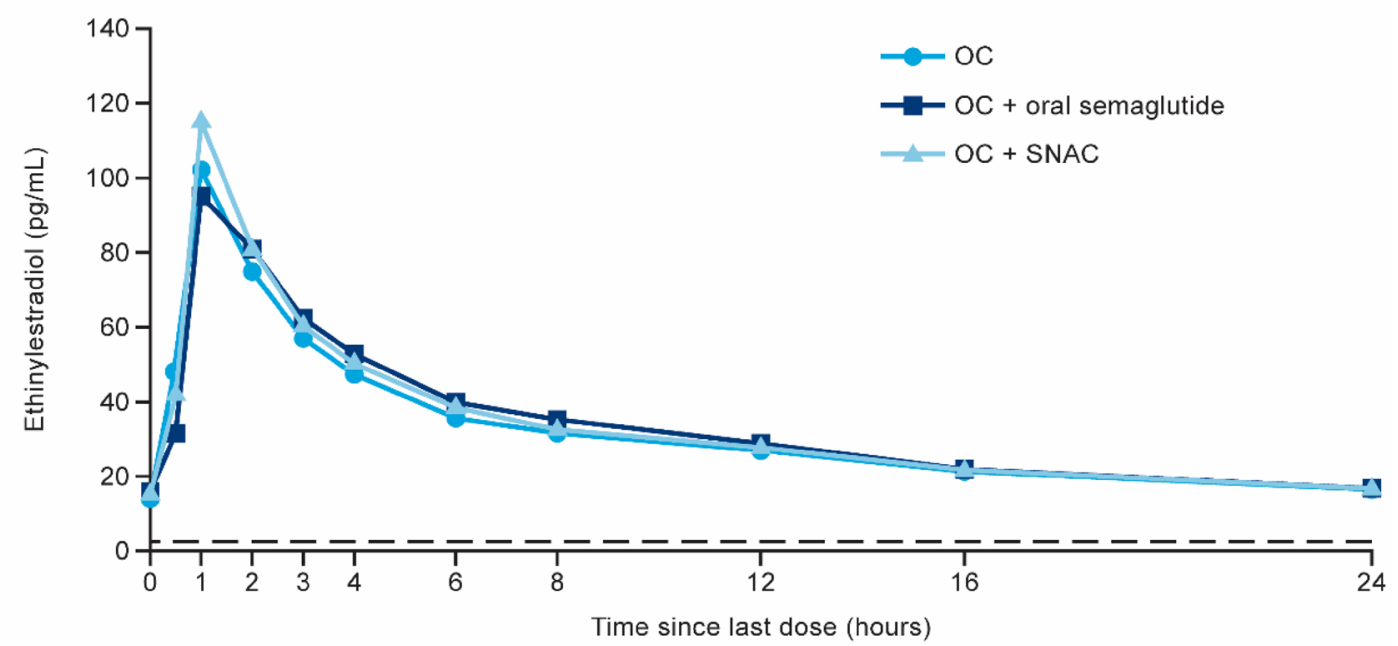

---- lower limit of quantification $(2.5 \mathrm{pg} / \mathrm{mL})$

(b) Levonorgestrel (steady state) \pm oral semaglutide \pm SNAC alone $(N=25)$

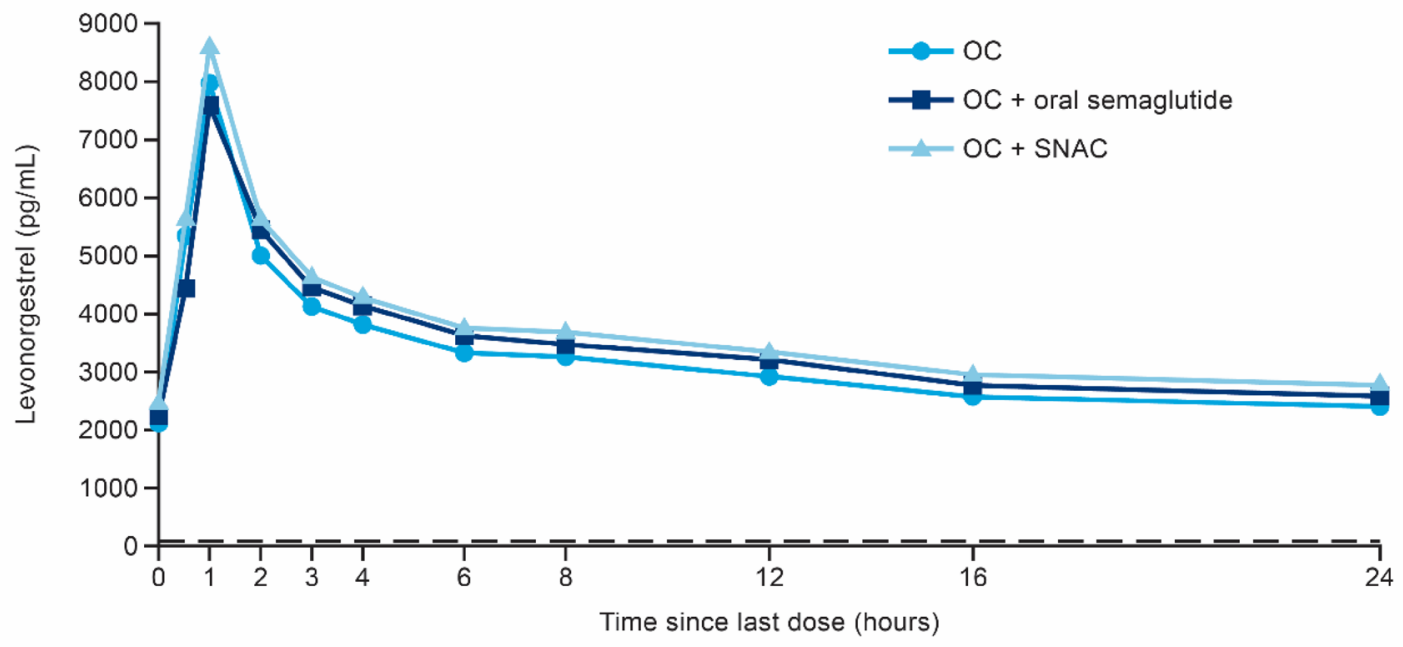

---- lower limit of quantification $(25 \mathrm{pg} / \mathrm{mL})$

Fig. 2 Mean concentration-time profiles for the primary endpoints: a $0-24 \mathrm{~h}$ of ethinylestradiol (steady state) \pm oral semaglutide \pm SNAC alone $(n=25)$; b $0-24 \mathrm{~h}$ of levonorgestrel (steady state) \pm oral semaglutide \pm SNAC alone $(n=25) ; \mathbf{c} 0-12 \mathrm{~h}$ of furosemide (single dose) \pm oral semaglutide $(n=39$; top panel $) \pm$ SNAC alone $(n=40$; lower panel); and $\mathbf{d} 0-96 \mathrm{~h}$ of rosuvastatin (single dose) \pm oral semaglutide $(n=33$; top panel $) \pm$ SNAC alone $(n=40$; lower panel $)$; insets show

\subsubsection{Trial 2 (Furosemide/Rosuvastatin)}

A total of 37 subjects $(90.2 \%)$ had at least one AE during Trial 2. AEs occurred primarily during oral semaglutide treatment, including the dose-escalation period. There were no deaths and no serious AEs reported in this trial. An
0-24 $\mathrm{h}$ interval with an expanded time scale. Oral semaglutide is the formulation of the active pharmaceutical ingredient semaglutide and the absorption enhancer SNAC $300 \mathrm{mg}$. The dashed line indicates the lower limit of quantification [2.5 pg/mL (a), $25 \mathrm{pg} / \mathrm{mL}(\mathbf{b}), 5 \mathrm{ng} / \mathrm{mL}$ (c), $0.1 \mathrm{ng} / \mathrm{mL}$ (d)]. OC combined oral contraceptive, SNAC sodium $\mathrm{N}$-(8-[2-hydroxybenzoyl] amino) caprylate (300 mg)

overview of treatment-emergent AEs is shown in Table 6. Similar to Trial 1, the majority of AEs were gastrointestinal disorders, occurring in 59\% (24/41) of subjects, and nausea was reported in 29\% (12/41) of subjects. There was one severe event of abdominal pain reported during the oral semaglutide alone period. Nervous system disorders, mainly 
(c) Furosemide (single dose) \pm oral semaglutide ( $N=39$; top panel) \pm SNAC alone ( $N=40$; lower panel)
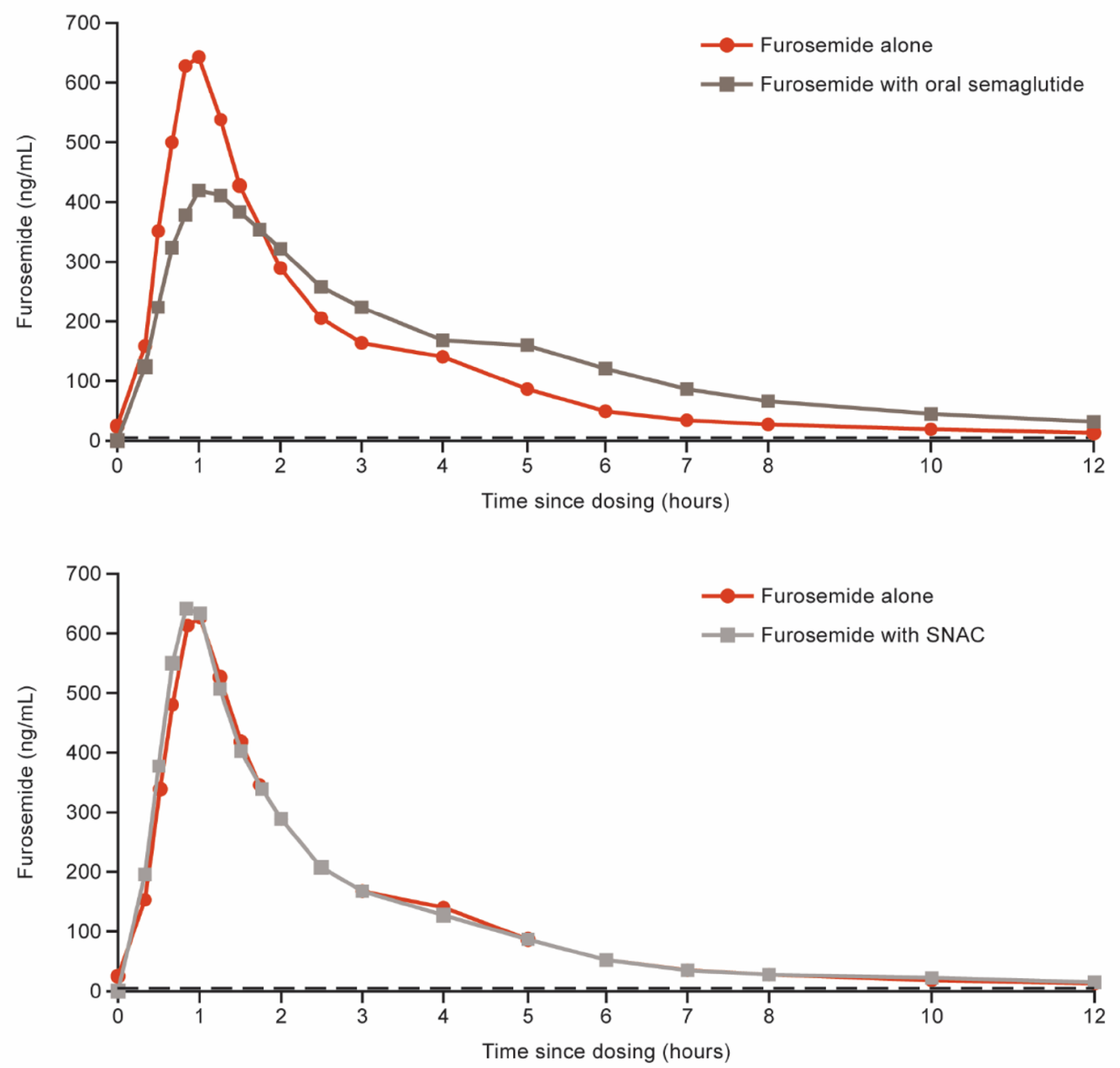

---- lower limit of quantification $(5 \mathrm{ng} / \mathrm{mL})$

Fig. 2 (continued)

headache, were the second most commonly reported AEs by organ class. There was one case of abnormally increased blood creatinine phosphokinase, which was reported as mild. The increase in blood creatinine kinase was most likely caused by physical exercise and was not considered to be clinically relevant.

\section{Discussion}

The main purpose of these studies was to assess the effect of oral semaglutide on the pharmacokinetics of ethinylestradiol, levonorgestrel, furosemide and rosuvastatin. In addition, the potential impact of the absorption enhancer SNAC alone was tested to differentiate between the effects caused by semaglutide and by SNAC. In Trial 1, no statistically significant pharmacokinetic interaction was observed when oral semaglutide was co-administered with ethinylestradiol or levonorgestrel, suggesting that oral semaglutide does not have an impact on the contraceptive effect. In line with these findings, a previous trial found that once-weekly subcutaneous semaglutide did not affect exposure of ethinylestradiol and levonorgestrel to any clinically relevant degree, even though a 20\% increase in levonorgestrel AUC was observed [9].

In Trial 2, co-administration of oral semaglutide with a single dose of furosemide resulted in a $28 \%$ increase in total furosemide exposure and a $34 \%$ decrease in the maximum furosemide concentration. There was no effect on the AUC when furosemide was co-administered with SNAC, but the $C_{\max }$ was slightly decreased. Co-administration of oral semaglutide with a single dose of rosuvastatin resulted in a $41 \%$ increase in total rosuvastatin exposure (and 10\% increase in 
(d) Rosuvastatin (single dose) \pm oral semaglutide ( $N=33$; top panel) \pm SNAC alone ( $N=40$; lower panel)
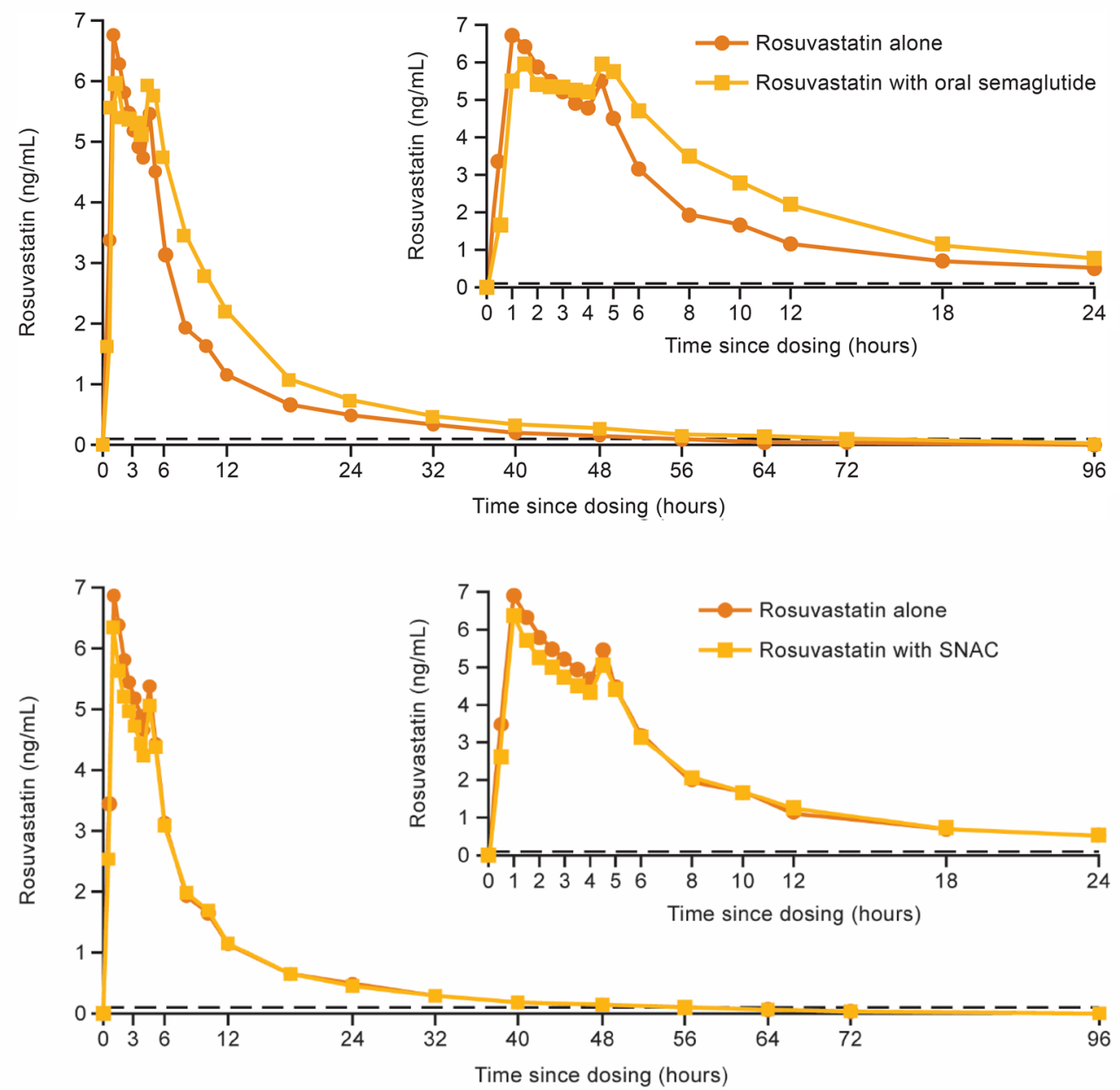

---- lower limit of quantification $(0.1 \mathrm{ng} / \mathrm{mL})$

Fig. 2 (continued)

maximum rosuvastatin concentration); however, there was no effect on exposure or $C_{\max }$ when rosuvastatin was co-administered with SNAC. Consequently, the effects observed when furosemide and rosuvastatin were coadministered with oral semaglutide should not be attributed to effects of SNAC on the BCRP, OAT1 and/or OAT3 and OATP1B1 transporters. Rather, they may be related to the GLP-1RA component of oral semaglutide, potentially due to a small delay in gastric emptying, a known effect of GLP1RAs that may influence the rate and extent of absorption of co-administered drugs [22]. Orally administered furosemide has poor bioavailability (47\%) and absorption of furosemide can be inconsistent $[29,41]$. The delay in gastric emptying caused by the GLP-1RA component of oral semaglutide could therefore explain the decrease in $C_{\max }$ and the increased total exposure with furosemide. The clinical relevance of the pharmacokinetic changes observed for furosemide and rosuvastatin have not been investigated in this trial; however, furosemide has a high variability in bioavailability between individuals $[29,42]$ and the dosing is generally adjusted individually in the clinic. In addition, furosemide has a broad therapeutic index and is generally well-tolerated. Similarly, rosuvastatin is generally well-tolerated [43, 44], and a similar increase in rosuvastatin exposure has previously been reported, concluding no clinical relevance [45]. Based on this evidence, we do not believe the results observed in the present trial with regards to furosemide and rosuvastatin are of any clinical relevance.

In Trials 1 and 2, a clinically relevant exposure of semaglutide was achieved as the $C_{\max }$ of semaglutide was similar to that seen with once-weekly subcutaneous semaglutide in patients with T2D [46]. 
(a) Ethinylestradiol and levonorgestrel

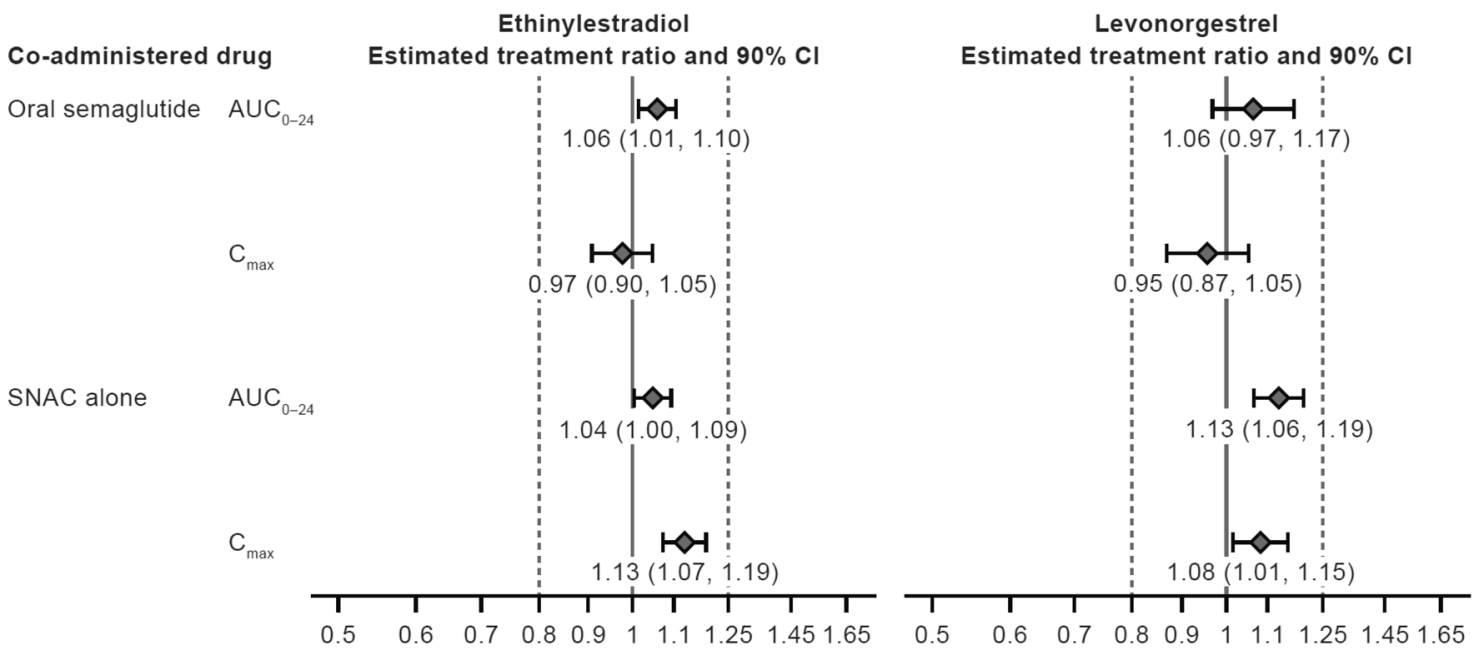

\section{(b) Furosemide and rosuvastatin}
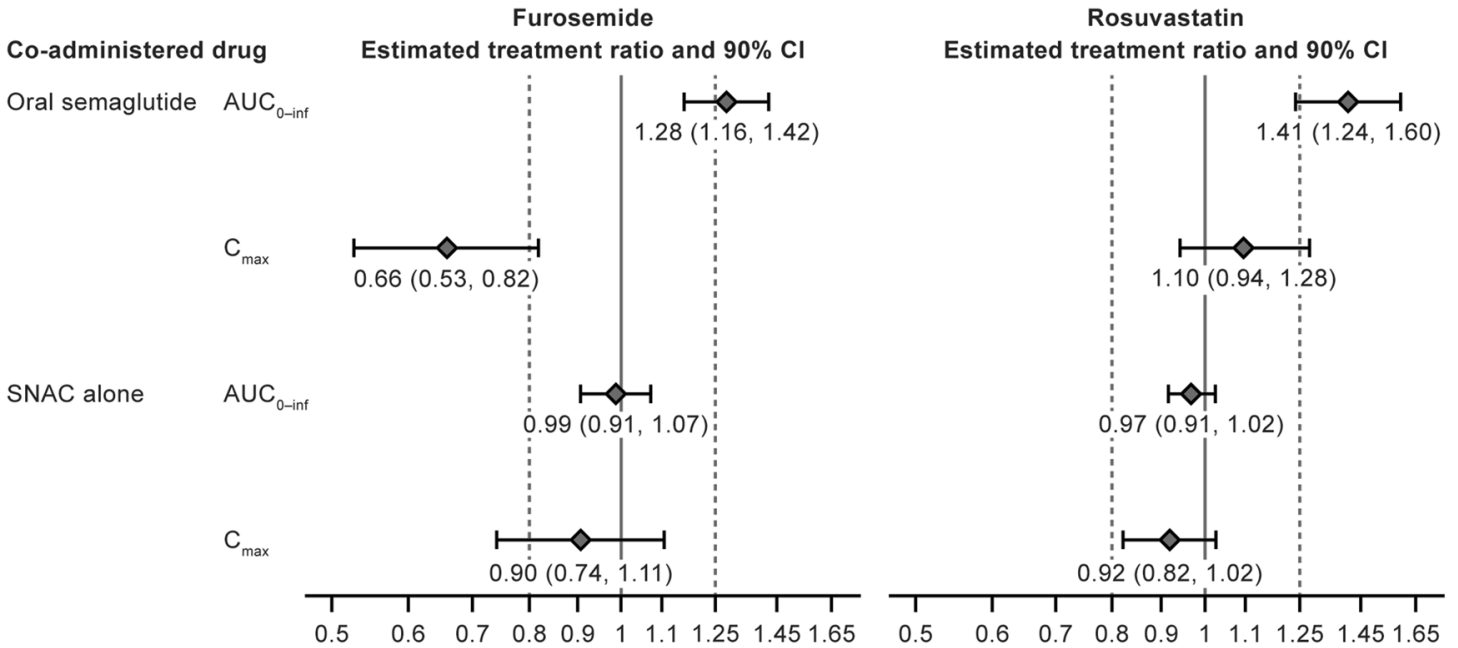

Fig. 3 Estimated AUC and $C_{\max }$ ratios (with 90\% CI) for ethinylestradiol and levonorgestrel (a) and furosemide and rosuvastatin (b) with co-administration of oral semaglutide or SNAC alone. No effect is confirmed if the $90 \% \mathrm{CI}$ is entirely within the pre-specified interval of $0.80-1.25$. The ANOVA model based on the log-transformed endpoint as dependent variable and subject and period (with/without co-administration of oral semaglutide or SNAC alone) as fixed fac-

In both trials, the safety and tolerability profile of oral semaglutide was consistent with previous trials and with the class effects of GLP-1RAs [16-19, 47-50]. A higher proportion of subjects experienced gastrointestinal AEs in the present studies than in the phase II dose-finding trial, which could be attributed to a faster dose-escalation regimen [15]. In Trial 1, vaginal haemorrhaging was a commonly reported AE; however, this is known to occur in postmenopausal women receiving hormone tors. Oral semaglutide is the formulation of the active pharmaceutical ingredient semaglutide and the absorption enhancer SNAC $300 \mathrm{mg}$. ANOVA analysis of variance, $A U C$ area under the plasma concentration-time curve, $A U C_{0-24}$ AUC from time zero to $24 \mathrm{~h}, A U C_{0-i n f}$ AUC from time zero to infinity, $C I$ confidence interval, $C_{\max }$ maximum concentration, $S N A C$ sodium $N$-(8-[2-hydroxybenzoyl] amino) caprylate

replacement therapy and was therefore likely related to OC dosing [51, 52]. Moderate and transient ALT and AST elevations were noted in five subjects. As the trial was not designed to assess the increased values of ALT and AST, it was not possible to distinguish between an effect of repeated OC treatments and the effect of coadministration of OC and oral semaglutide. However, a link between OC use and increased liver parameters has been proposed [53]. 
Table 2 Pharmacokinetic endpoints for ethinylestradiol (steady state) either alone or after co-administration with oral semaglutide or sodium $N$-(8-[2-hydroxybenzoyl] amino) caprylate alone

\begin{tabular}{|c|c|c|c|}
\hline Parameters & $\begin{array}{l}\text { OC alone } \\
(n=25)\end{array}$ & $\begin{array}{l}\text { OC }+ \text { SNAC alone } \\
(n=25)\end{array}$ & $\begin{array}{l}\text { OC + oral } \\
\text { semaglutide } \\
(n=25)\end{array}$ \\
\hline \multicolumn{4}{|l|}{$\mathrm{AUC}_{0-24}, \mathrm{pg} \cdot \mathrm{h} / \mathrm{mL}$} \\
\hline Geometric mean (CV) & $783.1(23.5)$ & $817.8(17.5)$ & $826.9(22.5)$ \\
\hline Arithmetic mean (SD) & $803.3(183.8)$ & 829.7 (144.9) & $846.1(181.6)$ \\
\hline \multicolumn{4}{|l|}{$C_{\max }, \mathrm{pg} / \mathrm{mL}$} \\
\hline Geometric mean $(\mathrm{CV})$ & $102.8(24.6)$ & $115.9(17.4)$ & $99.9(22.7)$ \\
\hline Arithmetic mean (SD) & $105.7(25.7)$ & $117.6(21.2)$ & $102.2(21.4)$ \\
\hline \multicolumn{4}{|l|}{$t_{1 / 2}, \mathbf{h}$} \\
\hline Geometric mean (CV) & $19.1(17.5)$ & $19.2(13.0)$ & $20.5(17.2)$ \\
\hline Arithmetic mean (SD) & $19.4(3.3)$ & $19.3(2.6)$ & $20.8(3.6)$ \\
\hline$t_{\max }, \mathbf{h}$, median $(\min ; \max )$ & $1.0(1.0 ; 2.0)$ & $1.0(1.0 ; 1.0)$ & $1.0(1.0 ; 3.0)$ \\
\hline
\end{tabular}

Oral semaglutide is the formulation of the active pharmaceutical ingredient semaglutide and the absorption enhancer SNAC $300 \mathrm{mg}$

$A U C_{0-24}$ area under the plasma concentration-time curve from time zero to $24 \mathrm{~h}, C_{\max }$ maximum concentration, $C V$ coefficient of variation, max maximum, min minimum, $O C$ combined oral contraceptive, $S D$ standard deviation, $S N A C$ sodium $N$-(8-[2-hydroxybenzoyl] amino) caprylate, $t_{1 / 2}$ terminal half-life, $t_{\max }$ time to reach maximum concentration

Table 3 Pharmacokinetic endpoints for levonorgestrel (steady state) either alone or after co-administration with oral semaglutide or sodium $\mathrm{N}$-(8-[2-hydroxybenzoyl] amino) caprylate alone

\begin{tabular}{llll}
\hline Parameters & OC alone $(n=25)$ & OC + SNAC alone $(n=25)$ & OC + oral semaglutide $(n=25)$ \\
\hline AUC $\mathbf{0 - 2 4}_{\mathbf{4}}, \mathbf{p g} \cdot \mathbf{h} / \mathbf{m L}$ & & & $82,478.3(34.1)$ \\
$\quad$ Geometric mean (CV) & $77,662.9(30.4)$ & $87,508.9(26.9)$ & $86,845.2(28,435.1)$ \\
Arithmetic mean (SD) & $81,045.3(24,564.9)$ & $90,516.1(24,534.6)$ & $7610.3(27.2)$ \\
$\boldsymbol{C}_{\mathbf{m a x}}, \mathbf{p g} / \mathbf{m L}$ & & & $7858.0(1927.8)$ \\
Geometric mean (CV) & $7974.6(28.2)$ & $8614.5(21.1)$ & $31.9(17.2)$ \\
Arithmetic mean (SD) & $8251.6(2081.4)$ & $8795.2(1819.2)$ & $32.3(5.5)$ \\
$\boldsymbol{t}_{\mathbf{1} / 2}, \mathbf{h}$ & & & $1.0(0.5 ; 1.0)$ \\
Geometric mean (CV) & $32.8(15.4)$ & $33.4(15.6)$ & $33.8(5.2)$ \\
Arithmetic mean (SD) & $33.2(5.0)$ & $1.0(1.0 ; 1.0)$ & \\
$\boldsymbol{t}_{\mathbf{m a x}}, \mathbf{h}$, median (min; max $)$ & $1.0(0.5 ; 4.0)$ & & \\
\hline
\end{tabular}

Oral semaglutide is the formulation of the active pharmaceutical ingredient semaglutide and the absorption enhancer SNAC 300 mg

$A U C_{0-24}$ area under the plasma concentration-time curve from time zero to $24 \mathrm{~h}, C_{\max }$ maximum concentration, $C V$ coefficient of variation, max maximum, min minimum, $O C$ combined oral contraceptive, SD standard deviation, SNAC sodium $N$-(8-[2-hydroxybenzoyl] amino) caprylate, $t_{1 / 2}$ terminal half-life, $t_{\max }$ time to reach maximum concentration

A potential limitation of these trials is that they had a onesequence crossover design and differences in observation/ exposure periods could make it difficult to compare safety and tolerability profiles between treatment periods. The trial population of healthy subjects differs from the target population for oral semaglutide; nevertheless, the criteria for participant selection were in accordance with the FDA and EMA guidelines for DDI clinical trials $[39,40]$ and the use of healthy subjects prevents the potential confounding effect of concomitant medications and co-morbidities. 
Table 4 Pharmacokinetic endpoints for furosemide (single dose) either alone or after co-administration with oral semaglutide or sodium $\mathrm{N}$-(8-[2-hydroxybenzoyl] amino) caprylate alone

\begin{tabular}{|c|c|c|c|c|}
\hline \multirow[t]{2}{*}{ Parameters } & \multicolumn{2}{|c|}{ Effect of oral semaglutide } & \multicolumn{2}{|l|}{ Effect of SNAC } \\
\hline & $\begin{array}{l}\text { Furosemide alone } \\
(n=39)\end{array}$ & $\begin{array}{l}\text { Furosemide }+ \text { oral } \\
\text { semaglutide } \\
(n=39)\end{array}$ & $\begin{array}{l}\text { Furosemide alone } \\
(n=40)\end{array}$ & $\begin{array}{l}\text { Furosemide }+ \\
\text { SNAC alone } \\
(n=40)\end{array}$ \\
\hline \multicolumn{5}{|l|}{$\mathrm{AUC}_{0-\infty}, \mathbf{n g} \cdot \mathbf{h} / \mathrm{mL}$} \\
\hline Geometric mean $(\mathrm{CV})$ & $1864.2(25.0)$ & $2393.8(32.2)$ & $1842.8(25.8)$ & $1816.3(33.2)$ \\
\hline Arithmetic mean (SD) & $1918.8(461.1)$ & $2517.1(874.3)$ & $1900.2(470.1)$ & $1912.0(631.1)$ \\
\hline \multicolumn{5}{|l|}{$C_{\max }, \mathrm{ng} / \mathrm{mL}$} \\
\hline Geometric mean (CV) & $847.2(54.2)$ & $556.9(67.6)$ & $821.9(57.8)$ & $743.7(68.5)$ \\
\hline Arithmetic mean (SD) & $959.7(505.0)$ & $665.6(405.4)$ & $942.0(510.9)$ & $890.1(532.8)$ \\
\hline \multicolumn{5}{|l|}{$t_{1 / 2}, \mathbf{h}$} \\
\hline Geometric mean $(\mathrm{CV})$ & $4.4(42.2)$ & $4.2(81.1)^{\mathrm{a}}$ & $4.4(41.7)$ & $4.3(44.9)^{\mathrm{b}}$ \\
\hline Arithmetic mean (SD) & $4.8(2.3)$ & $5.9(8.0)^{\mathrm{a}}$ & $4.8(2.3)$ & $4.8(3.1)^{\mathrm{b}}$ \\
\hline$t_{\max }, \mathbf{h}$, median $(\min ; \max )$ & $0.9(0.5 ; 4.1)$ & $1.3(0.5 ; 12.0)$ & $0.9(0.5 ; 4.1)$ & $0.8(0.4 ; 2.1)$ \\
\hline
\end{tabular}

The number of subjects in the analysis with/without oral semaglutide is lower due to subject withdrawals ( 2 subjects; 1 of these also affecting the number of subjects in the analysis with/without SNAC)

Oral semaglutide is the formulation of the active pharmaceutical ingredient semaglutide and the absorption enhancer SNAC 300 mg

Only subjects having evaluable profiles for both treatment periods (e.g. furosemide/rosuvastatin alone and furosemide/rosuvastatin + oral semaglutide or furosemide/rosuvastatin alone + furosemide/rosuvastatin + SNAC alone) were considered for each comparison. The comparisons are presented separately due to the differences in the number of subjects; ${ }^{\mathrm{a}} n=34,{ }^{\mathrm{b}} n=37$

$A U C_{0-\infty}$ area under the plasma concentration-time curve from time zero to infinity, $C_{\max }$ maximum concentration, $C V$ coefficient of variation, max maximum, min minimum, $S D$ standard deviation, $S N A C$ sodium $N$-(8-[2-hydroxybenzoyl] amino) caprylate, $t_{1 / 2}$ terminal half-life, $t_{\text {max }}$ time to reach maximum concentration

Table 5 Pharmacokinetic endpoints for rosuvastatin (single dose) either alone or after co-administration with oral semaglutide or sodium $N$-(8-[2-hydroxybenzoyl] amino) caprylate alone

\begin{tabular}{|c|c|c|c|c|}
\hline \multirow[t]{2}{*}{ Parameters } & \multicolumn{2}{|c|}{ Effect of oral semaglutide } & \multicolumn{2}{|c|}{ Effect of SNAC } \\
\hline & $\begin{array}{l}\text { Rosuvastatin } \\
\text { alone } \\
(n=33)\end{array}$ & $\begin{array}{l}\text { Rosuvastatin }+ \text { oral } \\
\text { semaglutide } \\
(n=33)\end{array}$ & $\begin{array}{l}\text { Rosuvastatin } \\
\text { alone } \\
(n=40)\end{array}$ & $\begin{array}{l}\text { Rosuvastatin }+ \\
\text { SNAC alone } \\
(n=40)\end{array}$ \\
\hline \multicolumn{5}{|l|}{$\mathrm{AUC}_{0-\infty}, \mathbf{n g} \cdot \mathbf{h} / \mathrm{mL}$} \\
\hline Geometric mean $(\mathrm{CV})$ & $64.1(45.3)$ & $90.3(58.0)$ & $64.1(42.9)$ & $62.0(39.6)$ \\
\hline Arithmetic mean (SD) & $70.3(31.4)$ & $104.6(61.1)$ & $69.7(29.7)$ & $66.8(28.2)$ \\
\hline \multicolumn{5}{|l|}{$C_{\max }, \mathrm{ng} / \mathrm{mL}$} \\
\hline Geometric mean $(\mathrm{CV})$ & $7.5(63.0)$ & $8.3(69.3)$ & $7.6(61.5)$ & $7.0(58.5)$ \\
\hline Arithmetic mean (SD) & $8.9(5.4)$ & $10.2(7.8)$ & $8.9(5.3)$ & $8.2(5.3)$ \\
\hline \multicolumn{5}{|l|}{$t_{1 / 2}, \mathbf{h}$} \\
\hline Geometric mean (CV) & $17.1(54.5)$ & $20.5(47.7)$ & $17.0(51.4)$ & $16.7(35.4)$ \\
\hline Arithmetic mean (SD) & $19.9(13.9)$ & $22.6(10.6)$ & $19.5(12.9)$ & $17.7(6.4)$ \\
\hline$t_{\max }, \mathbf{h}$, median $(\min ; \max )$ & $1.0(0.5 ; 5.0)$ & $1.5(1.0 ; 10.1)$ & $1.0(0.5 ; 5.0)$ & $1.0(1.0 ; 5.0)$ \\
\hline
\end{tabular}

The number of subjects in the analysis with/without oral semaglutide is lower due to loss of blood samples for pharmacokinetic assessment (6 subjects) and subject withdrawals (2 subjects; 1 of these also affecting the number of subjects in the analysis with/without SNAC)

Oral semaglutide is the formulation of the active pharmaceutical ingredient semaglutide and the absorption enhancer SNAC $300 \mathrm{mg}$

Only subjects having evaluable profiles for both treatment periods (e.g. furosemide/rosuvastatin alone and furosemide/rosuvastatin + oral semaglutide or furosemide/rosuvastatin alone + furosemide/rosuvastatin + SNAC alone) were considered for each comparison. The comparisons are presented separately due to the differences in the number of subjects

$A U C_{0-\infty}$ area under the plasma concentration-time curve from time zero to infinity, $C_{\text {max }}$ maximum concentration, $C V$ coefficient of variation, max maximum, min minimum, $S D$ standard deviation, $S N A C$ sodium $N$-(8-[2-hydroxybenzoyl] amino) caprylate, $t_{1 / 2}$ terminal half-life, $t_{\max }$ time to reach maximum concentration 
Table 6 Overview of treatmentemergent adverse events in healthy postmenopausal women (Trial 1) and healthy male and female subjects (Trial 2)

\begin{tabular}{lll}
\hline Adverse events & $\begin{array}{l}\text { Trial 1 } \\
\text { (ethinylestradiol/ } \\
\text { levonorgestrel) }\end{array}$ & $\begin{array}{l}\text { Trial 2 } \\
\text { (furosemide/ } \\
\text { rosuvastatin) }\end{array}$ \\
\hline$n$ & 25 & 41 \\
Adverse events, $n(\%)$ & $24(96.0)$ & $37(90.2)$ \\
Serious adverse events, $n(\%)$ & $0(0.0)$ & $0(0.0)$ \\
Adverse events by organ class, $n(\%)$ & & \\
Gastrointestinal disorders & $20(80.0)$ & $24(58.5)$ \\
Metabolism and nutrition disorders & $20(80.0)$ & $8(19.5)$ \\
Reproductive system and breast disorders & $17(68.0)$ & $1(2.4)$ \\
General disorders and administration site conditions & $9(36.0)$ & $13(31.7)$ \\
Nervous system disorders & $9(36.0)$ & $22(53.7)$ \\
Infections and infestations & $7(28.0)$ & $11(26.8)$ \\
Investigations & $5(20.0)$ & $1(2.4)$ \\
Musculoskeletal and connective tissue disorders & $4(16.0)$ & $10(24.4)$ \\
Psychiatric disorders & $3(12.0)$ & $3(7.3)$ \\
Skin and subcutaneous disorders & $3(12.0)$ & $2(4.9)$ \\
Immune system disorders & $1(4.0)$ & NR \\
Injury, poisoning and procedural complications & $1(4.0)$ & $7(17.1)$ \\
Respiratory, thoracic and mediastinal disorders & $1(4.0)$ & $15(36.6)$ \\
Vascular disorders & $1(4.0)$ & NR \\
Ear and labyrinth disorders & $\mathrm{NR}$ & $3(7.3)$ \\
Eye disorders & $\mathrm{NR}$ & $1(2.4)$ \\
Cardiac disorders & $\mathrm{NR}$ & $1(2.4)$ \\
\hline
\end{tabular}

$N R$ not reported

\section{Conclusion}

When co-administered with oral contraception, neither oral semaglutide nor SNAC alone had a statistically significant effect on the exposure of ethinylestradiol or levonorgestrel. Oral semaglutide resulted in a small increase in exposure to furosemide and rosuvastatin. The clinical relevance of the increased exposure of furosemide and rosuvastatin was not assessed in this trial. However, since furosemide has a broad therapeutic index and is generally dose-adjusted individually, and since rosuvastatin is generally well-tolerated with similar increases in exposures previously being reported as not clinically relevant, the results observed in the present trial are expected to be of no clinical relevance.

Oral semaglutide was found to be well-tolerated in combination with these drugs and no unexpected safety issues were identified.

Supplementary Information The online version contains supplementary material available at (https://doi.org/10.1007/ s40262-020-00976-x).

Acknowledgements Writing support was provided by Debbie Day of Axis, a division of Spirit Medical Communications Group Limited, supported by Novo Nordisk A/S in accordance with Good Publication Practice (GPP3) guidelines (http://www.ismpp.org/gpp3). The authors would like to thank all the participants, investigators and trial-site staff who were involved in the conduct of the trials, Michael Pilgaard Andersen (Novo Nordisk A/S) for support with the bioanalyses and Christin Løth Hertz (Novo Nordisk A/S) for reviewing the manuscript.

Author Contributions All authors participated in the trial design and/or data analysis and interpretation and participated in writing the manuscript together with medical writing services provided by the sponsor. Astrid Breitschaft (Trial 1) and Muna Albayaty (Trial 2) were involved in the trial conduct and acquisition of data. All authors have approved the submitted manuscript.

\section{Compliance with Ethical Standards}

Funding Both trials were sponsored by Novo Nordisk A/S, Søborg, Denmark.

Conflict of interest Tine A. Bækdal, Erik Christiansen, Azadeh Houshmand-Øregaard, Easwaran Manigandan and Andreas B. Jordy are Novo Nordisk employees. Tine A. Bækdal, Thomas W. Anderson, Erik Christiansen, Azadeh Houshmand-Øregaard and Easwaran Manigandan own stocks or shares in Novo Nordisk. Thomas W. Anderson is a former employee of Novo Nordisk.

Ethical approval All procedures performed in studies involving human subjects were in accordance with the ethical standards of the institutional and/or national research committee and with the 1964 Helsinki Declaration and its later amendments or comparable ethical standards. 
Consent to participate Informed consent was obtained from all individual subjects included in these trials.

Open Access This article is licensed under a Creative Commons Attribution-NonCommercial 4.0 International License, which permits any non-commercial use, sharing, adaptation, distribution and reproduction in any medium or format, as long as you give appropriate credit to the original author(s) and the source, provide a link to the Creative Commons licence, and indicate if changes were made. The images or other third party material in this article are included in the article's Creative Commons licence, unless indicated otherwise in a credit line to the material. If material is not included in the article's Creative Commons licence and your intended use is not permitted by statutory regulation or exceeds the permitted use, you will need to obtain permission directly from the copyright holder. To view a copy of this licence, visit http://creativecommons.org/licenses/by-nc/4.0/.

\section{References}

1. Tran KL, Park YI, Pandya S, Muliyil NJ, Jensen BD, Huynh K, et al. Overview of glucagon-like peptide-1 receptor agonists for the treatment of patients with type 2 diabetes. Am Health Drug Benefits. 2017;10(4):178-88.

2. Sorli C, Harashima SI, Tsoukas GM, Unger J, Karsbol JD, Hansen $\mathrm{T}$, et al. Efficacy and safety of once-weekly semaglutide monotherapy versus placebo in patients with type 2 diabetes (SUSTAIN 1): a double-blind, randomised, placebo-controlled, parallelgroup, multinational, multicentre phase $3 \mathrm{a}$ trial. Lancet Diabetes Endocrinol. 2017;5(4):251-60.

3. Ahrén B, Masmiquel L, Kumar H, Sargin M, Karsbol JD, Jacobsen $\mathrm{SH}$, et al. Efficacy and safety of once-weekly semaglutide versus once-daily sitagliptin as an add-on to metformin, thiazolidinediones, or both, in patients with type 2 diabetes (SUSTAIN 2): a 56-week, double-blind, phase $3 \mathrm{a}$, randomised trial. Lancet Diabetes Endocrinol. 2017;5(5):341-54.

4. Ahmann AJ, Capehorn M, Charpentier G, Dotta F, Henkel E, Lingvay I, et al. Efficacy and safety of once-weekly semaglutide versus exenatide ER in subjects with type 2 diabetes (SUSTAIN 3): a 56-week, open-label, randomized clinical trial. Diabetes Care. 2018;41(2):258-66.

5. Aroda VR, Bain SC, Cariou B, Piletic M, Rose L, Axelsen M, et al. Efficacy and safety of once-weekly semaglutide versus once-daily insulin glargine as add-on to metformin (with or without sulfonylureas) in insulin-naive patients with type 2 diabetes (SUSTAIN 4): a randomised, open-label, parallel-group, multicentre, multinational, phase $3 \mathrm{a}$ trial. Lancet Diabetes Endocrinol. 2017;5(5):355-66.

6. Rodbard HW, Lingvay I, Reed J, de la Rosa R, Rose L, Sugimoto $\mathrm{D}$, et al. Semaglutide Added to Basal Insulin in Type 2 Diabetes (SUSTAIN 5): a randomized, controlled trial. J Clin Endocrinol Metab. 2018;103(6):2291-301.

7. Jensen L, Helleberg H, Roffel A, van Lier JJ, Bjørnsdottir I, Pedersen PJ, et al. Absorption, metabolism and excretion of the GLP-1 analogue semaglutide in humans and nonclinical species. Eur J Pharm Sci. 2017;104:31-41.

8. Lau J, Bloch P, Schäffer L, Pettersson I, Spetzler J, Kofoed J, et al. Discovery of the once-weekly glucagon-like peptide-1 (GLP-1) analogue semaglutide. J Med Chem. 2015;58(18):7370-80.

9. Kapitza C, Nosek L, Jensen L, Hartvig H, Jensen CB, Flint A. Semaglutide, a once-weekly human GLP-1 analog, does not reduce the bioavailability of the combined oral contraceptive, ethinylestradiol/levonorgestrel. J Clin Pharmacol. 2015;55(5):497-504.
10. Nauck M, Petrie J, Sesti G, Mannucci E, Courrèges J, Lindegaard $\mathrm{M}$, et al. A phase 2, randomized, dose-finding study of the novel once-weekly human GLP-1 analog, semaglutide, compared with placebo and open-label liraglutide in patients with type 2 diabetes. Diabetes Care. 2016;39:231-41.

11. Granhall C, Donsmark M, Blicher TM, Golor G, Søndergaard FL, Thomsen M, et al. Safety and pharmacokinetics of single and multiple ascending doses of the novel oral human GLP-1 analogue, oral semaglutide, in healthy subjects and subjects with type 2 diabetes. Clin Pharmacokinet. 2019;58(6):781-91.

12. Buckley ST, Bækdal TA, Vegge A, Maarbjerg SJ, Pyke C, Ahnfelt-Rønne J, et al. Transcellular stomach absorption of a derivatized glucagon-like peptide-1 receptor agonist. Sci Transl Med. 2018;10(467):eaar7047.

13. Karsdal MA, Riis BJ, Mehta N, Stern W, Arbit E, Christiansen $\mathrm{C}$, et al. Lessons learned from the clinical development of oral peptides. Br J Clin Pharmacol. 2015;79(5):720-32.

14. Fu AZ, Qiu Y, Radican L. Impact of fear of insulin or fear of injection on treatment outcomes of patients with diabetes. Curr Med Res Opin. 2009;25(6):1413-20.

15. Davies M, Pieber TR, Hartoft-Nielsen ML, Hansen OKH, Jabbour S, Rosenstock J. Effect of oral semaglutide compared with placebo and subcutaneous semaglutide on glycemic control in patients with type 2 diabetes: a randomized clinical trial. JAMA. 2017;318(15):1460-70.

16. Aroda VR, Rosenstock J, Terauchi Y, Altuntas Y, Lalic NM, Morales Villegas EC, et al. PIONEER 1: randomized clinical trial comparing the efficacy and safety of oral semaglutide monotherapy with placebo in patients with type 2 diabetes. Diabetes Care. 2019;42(9):1724-32.

17. Rosenstock J, Allison D, Birkenfeld AL, Blicher TM, Deenadayalan S, Jacobsen JB, et al. Effect of additional oral semaglutide vs sitagliptin on glycated hemoglobin in adults with type 2 diabetes uncontrolled with metformin alone or with sulfonylurea: the PIONEER 3 randomized clinical trial. JAMA. 2019;321(15):1466-80.

18. Pratley R, Amod A, Hoff ST, Kadowaki T, Lingvay I, Nauck M, et al. Oral semaglutide versus subcutaneous liraglutide and placebo in type 2 diabetes (PIONEER 4): a randomised, doubleblind, phase 3a trial. Lancet. 2019;394(10192):39-50.

19. Granhall C, Sondergaard FL, Thomsen M, Anderson TW. Pharmacokinetics, safety and tolerability of oral semaglutide in subjects with renal impairment. Clin Pharmacokinet. 2018;57(12):1571-80.

20. Baekdal TA, Thomsen M, Kupcova V, Hansen CW, Anderson TW. Pharmacokinetics, safety, and tolerability of oral semaglutide in subjects with hepatic impairment. J Clin Pharmacol. 2018;58(10):1314-23.

21. Hurren KM, Pinelli NR. Drug-drug interactions with glucagon-like peptide-1 receptor agonists. Ann Pharmacother. 2012;46(5):710-7.

22. Hjerpsted JB, Flint A, Brooks A, Axelsen MB, Kvist T, Blundell J. Semaglutide improves postprandial glucose and lipid metabolism, and delays first-hour gastric emptying in subjects with obesity. Diabetes Obes Metab. 2018;20(3):610-9.

23. Bækdal TA, Borregaard J, Hansen CW, Thomsen M, Anderson TW. Effect of oral semaglutide on the pharmacokinetics of lisinopril, warfarin, digoxin, and metformin in healthy subjects. Clin Pharmacokinet. 2019;58(9):1193-203.

24. Fotherby K. Bioavailability of orally administered sex steroids used in oral contraception and hormone replacement therapy. Contraception. 1996;54(2):59-69.

25. von Richter O, Burk O, Fromm MF, Thon KP, Eichelbaum M, Kivisto KT. Cytochrome P450 3A4 and P-glycoprotein expression in human small intestinal enterocytes and hepatocytes: a comparative analysis in paired tissue specimens. Clin Pharmacol Ther. 2004;75(3):172-83. 
26. Liu Y-Q, Yuan L-M, Gao Z-Z, Xiao Y-S, Sun H-Y, Yu L-S, et al. Dimerization of human uridine diphosphate glucuronosyltransferase allozymes 1A1 and 1A9 alters their quercetin glucuronidation activities. Sci Rep. 2016;6:23763.

27. Zhang H, Cui D, Wang B, Han YH, Balimane P, Yang Z, et al. Pharmacokinetic drug interactions involving 17alpha-ethinylestradiol: a new look at an old drug. Clin Pharmacokinet. 2007;46(2):133-57.

28. Data on File, Novo Nordisk, 2015.

29. Boles LL, Schoenwald RD. Furosemide (Frusemide) A pharmacokinetic/pharmacodynamic review (part I). Clin Pharmacokinet. 1990;18(5):381-408.

30. Martin PD, Warwick MJ, Dane AL, Brindley C, Short T. Absolute oral bioavailability of rosuvastatin in healthy white adult male volunteers. Clin Ther. 2003;25(11):2822-35.

31. Generaux GT, Bonomo FM, Johnson M, Mahar Doan KM. Impact of SLCO1B1 (OATP1B1) and ABCG2 (BCRP) genetic polymorphisms and inhibition on LDL-C lowering and myopathy of statins. Xenobiotica. 2011;41(8):639-51.

32. Data on File, Novo Nordisk, 2015.

33. Food and Drug Administration. Clinical drug interaction studiesstudy design, data analysis, and clinical implications. Guidance for industry. Rockville: FDA; 2017.

34. Novo Nordisk A/S. A trial investigating the influence of oral semaglutide on pharmacokinetics of ethinylestradiol and levonorgestrel in an oral contraceptive combination drug in healthy postmenopausal females [ClinicalTrials.gov identifier NCT02845219]. National Institutes of Health, ClinicalTrials.gov. https://clinicaltr ials.gov. Accessed 10 Dec 2020

35. Novo Nordisk A/S. A trial investigating the effect of oral semaglutide on the pharmacokinetics of furosemide and rosuvastatin in healthy subjects [ClinicalTrials.gov identifier NCT03010475]. National Institutes of Health, ClinicalTrials.gov. https://clinicaltr ials.gov. Accessed 10 Dec 2020.

36. World Medical Association. Declaration of Helsinki. Recommendations guiding medical doctors in biomedical research involving human subjects. 48th WMA General Assembly. Somerset West, Republic of South Africa; 1996.

37. European Medicines Agency. ICH harmonised tripartite guideline. Guideline for good clinical practice E6(R1), Step 4; 1996. https:// www.ema.europa.eu/en/documents/scientific-guideline/ich-e6-r1guideline-good-clinical-practice_en.pdf. Accessed 10 Dec 2020.

38. Food and Drug Administration. Foreign clinical studies not conducted under an IND. FDA Code of Federal Regulations, 21 CFR $312.120 ; 2014$

39. Food and Drug Administration. Drug interaction studies - study design, data analysis, implications for dosing, and labeling recommendations. Draft Guidance. Silver Spring: Center for Drug Evaluation and Research, Food and Drug Administration; 2012.

40. European Medicines Agency. Guideline on the investigation of drug interactions. London: European Medicines Agency; 2012.
41. Haegeli L, Brunner-La Rocca HP, Wenk M, Pfisterer M, Drewe J, Krähenbühl S, et al. Sublingual administration of furosemide: new application of an old drug. Br J Clin Pharmacol. 2007;64(6):804-9.

42. Grahnen A, Hammarlund M, Lundqvist T. Implications of intraindividual variability in bioavailability studies of furosemide. Eur J Clin Pharmacol. 1984;27(5):595-602.

43. Hu M, Cheung BM, Tomlinson B. Safety of statins: an update. Ther Adv Drug Saf. 2012;3(3):133-44.

44. Ramkumar S, Raghunath A, Raghunath S. Statin therapy: review of safety and potential side effects. Acta Cardiol Sin. 2016;32(6):631-9.

45. Cooper KJ, Martin PD, Dane AL, Warwick MJ, Schneck DW, Cantarini W. Effect of itraconazole on the pharmacokinetics of rosuvastatin. Clin Pharmacol Ther. 2003;73(4):322-9.

46. Petri KCC, Ingwersen SH, Flint A, Zacho J, Overgaard RV. Exposure-response analysis for evaluation of semaglutide dose levels in type 2 diabetes. Diabetes Obes Metab. 2018;20(9):2238-45.

47. Mosenzon O, Blicher TM, Rosenlund S, Eriksson JW, Heller S, Holm Hels O. Efficacy and safety of oral semaglutide in patients with type 2 diabetes and moderate renal impairment (PIONEER 5): a placebo-controlled, randomised, phase 3 a trial. Lancet Diabetes Endocrinol. 2019;7(7):515-27.

48. Pieber TR, Bode B, Mertens A, Cho YM, Christiansen E, Hertz CL. Efficacy and safety of oral semaglutide with flexible dose adjustment versus sitagliptin in type 2 diabetes (PIONEER 7): a multicentre, open-label, randomised, phase 3a trial. Lancet Diabetes Endocrinol. 2019;7(7):528-39.

49. Rodbard HW, Rosenstock J, Canani LH, Deerochanawong C, Gumprecht J, Lindberg S $\varnothing$, et al. PIONEER 2 Investigators. Oral semaglutide versus empagliflozin in patients with type 2 diabetes uncontrolled on metformin: the PIONEER 2 trial. Diabetes Care. 2019;42(12):2272-81.

50. Zinman B, Aroda VR, Buse JB, Cariou B, Harris SB, Hoff ST, Pedersen KB, Tarp-Johansen MJ, Araki E. PIONEER 8 Investigators. Efficacy, safety, and tolerability of oral semaglutide versus placebo added to insulin with or without metformin in patients with type 2 diabetes: the PIONEER 8 trial. Diabetes Care. 2019;42(12):2262-71.

51. Symons J, Kempfert N, Speroff L. Vaginal bleeding in postmenopausal women taking low-dose norethindrone acetate and ethinyl estradiol combinations. The FemHRT Study Investigators. Obstet Gynecol. 2000;96(3):366-72.

52. Collins J, Crosignani PG. Endometrial bleeding. Hum Reprod Update. 2007;13(5):421-31.

53. Dickerson J, Bressler R, Christian CD. Liver function tests and low-dose estrogen oral contraceptives. Contraception. 1980;22(6):597-603. 